\title{
MASCULINIDADE E SEXUALIDADE: NARRATIVAS DOS GAROTOS DE PROGRAMA, QUE ATUAM EM SAUNAS, NA CIDADE DE SALVADOR- BAHIA ${ }^{12}$
}

João Diogenes Ferreira dos Santos ${ }^{3}$

No momento que escrevo este artigo, o Brasil enfrenta a pandemia da COVID-19, que ocasionou medidas restritivas, adotadas pelas autoridades municipais e estaduais, tais como evitar aglomeração e suspender atividades comerciais ditas não essenciais. $O$ isolamento social, sendo uma dessas medidas, me impede em andar pelo centro da cidade de Salvador-BA, flanando e investigando os meandros do traçado urbano, onde em suas franjas se localizam espaços que permitem encontros sexuais, eróticos e amorosos proibidos pelas regras morais e o controle dos papeis de gênero. A restrição de flanar pelas ruas da capital baiana me levou a pensar em um trecho do livro de João do Rio $\left(2008\right.$, p. 31) ${ }^{4}$, quando o autor carioca, do início do século XX, afirma:

Flanar! Aí está um verbo universal sem entradas nos dicionários, que não pertencem a nenhuma língua! Que significa flanar? Flanar é ser vagabundo e refletir, é ser basbaque e comentar, ter o vírus da observação ligado ao da vadiagem [ócio]. Flanar é ir por aí, de manhã, de dia, à noite [...]

$\mathrm{O}$ isolamento também fez com que minhas memórias subterrâneas emergissem. Trato memória, neste artigo, dentro da perspectiva de Pollak (1989, p. 4), quando o autor sublinha que "[...] memórias subterrâneas que prosseguem seu trabalho de subversão no silêncio e de maneira quase imperceptível afloram em momentos de crise em sobressaltos ${ }^{1}$ DOI 10.29388/978-65-86678-76-5-f.139-158

${ }^{2}$ Este capítulo é uma versão do Relatório do Estágio Pós-Doutoral, com a pesquisa, intitulada "Juventude e Sexualidade: Trajetória de Vida dos "Garotos de Programa" na cidade de Salvador- Bahia", sob a supervisão do prof.Dr. Milton Júlio de Carvalho Filho, realizado no Instituto de Humanidades, Artes e Ciências Milton Santos - IHADC da Universidade Federal da Bahia - UFBA, no período de março de 2019 a março de 2020.

${ }^{3}$ Doutor em Ciências Sociais, professor titular da Universidade Estadual de Feira de Santana - UEFS e docente do Programa de Pós-Graduação em Memória, Linguagem e Sociedade da Universidade Estadual do Sudoeste da Bahia -UESB.

${ }^{4}$ João Paulo Emílio Cristovão dos Santos Coelho Barreto (1881-1921), conhecido pelo seu pseudônimo artístico João do Rio, escreveu a obra "A alma encantadora das ruas", em 1908, a partir das crônicas e reportagens das diferentes personagens que transitam nas ruas da cidade do Rio de Janeiro-RJ, no início do século XX. 
bruscos e exacerbado". Portanto, ao escutar minhas memórias, lembrei quando flanei pelas ruas do centro soteropolitano e deparei com um local, denominado de sauna ${ }^{5}$, onde os encontros sexuais entre homens se realizavam longe dos olhares moralistas. Neste ambiente, pela primeira vez, constatei que garotos de programa ${ }^{6}$ existiam, sabia da existência dos mesmos através dos anúncios publicados nos jornais impressos de grande circulação na cidade. Em um dia quente de verão, no mês de janeiro de 2004, entrei, mediante ao pagamento de uma taxa, nesse espaço comercial privado. $O$ espanto se fez presente nesse itinerário ao desconhecido, meu "olhar basbaque" observou alguns homens que procuravam outros homens no intuito de realizar seus desejos sexuais mediante ao pagamento.

A partir deste contato ímpar, associado à minha trajetória acadêmica ${ }^{7}$, me veio à inquietação, ou melhor dizendo, seguindo a linha do pensamento de João do Rio (2008), fui contagiado pelo "vírus da observação" do flanar, pois passei a querer desvendar o mundo que se apresentava para mim. Para além do vaguear sem propósito pelas ruas do centro da cidade, nas horas vagas, passei a conhecer outras saunas em Salvador e em diferentes cidades no Brasil (Recife, João Pessoa, Fortaleza, São Paulo, Rio de Janeiro, Brasília, Florianópolis). A experiência em ser andarilho urbano urdiu a ideia inicial de pesquisar as pessoas que frequentavam esses locais, que aparentemente são invisíveis na trama urbana e improváveis ao controle dos papeis de gênero estabelecidos.

Depois de 15 (quinze) anos do primeiro contato que tive com o universo das saunas, as convergências da vida possibilitaram que eu fizesse estágio pós-doutoral no Instituto de Humanidades, Artes e Ciências Milton Santos da Universidade Federal da Bahia, sob a supervisão do professor Milton Júlio Carvalho Filho. Por meio desse estágio, transitei de andarilho urbano para pesquisador. Esta metamorfose possibilitou entrar em contato com estudos e pesquisas que tratam de temas relativos à sexualidade e ao mercado do sexo masculino. Essa incursão me ofereceu uma nova perspectiva que transitou de um "ser basbaque" para um intér-

\footnotetext{
${ }^{5}$ A sauna, situada no centro da cidade de Salvador-BA, encerrou suas atividades no final da primeira década do século XXI.

${ }^{6}$ Conhecidos também como boys, michês, prostitutos, profissionais do sexo, dentre outros termos, de duas saunas na cidade de Salvador-BA. Neste artigo, irei denominálos como Garotos de Programa, conforme esses jovens se chamam e se reconhecem no cotidiano das saunas estudadas. O termo programa, popularmente, conota os serviços sexuais e eróticos oferecidos tanto por garotos como garotas no mercado do sexo.

7 A minha trajetória acadêmica consiste na realização de pesquisas, estudos e orientações sobre diferentes aspectos referentes à infância, adolescência e juventude, e com diversas publicações que versam sobre o tema.
} 
prete das diferentes narrativas, discursos, gestos, performances, experiências, regras e comportamentos relativos ao emaranhado universo das saunas.

Ser errante em um novo percurso me fez caminhar por veredas desconhecidas da investigação etnográfica. Por isto, os meus primeiros passos foram acessar nas plataformas digitais os trabalhos etnográficos no campo da sexualidade e da masculinidade, bem como a discussão teórica e metodológica a respeito da etnografia. Somei a esse material, a leitura do livro coordenado pelo antropólogo espanhol Joan Pujada (2010), que possibilitou erigir o percurso metodológico, levando em consideração as reflexões deste autor, quando afirma:

La etnografía como proceso, que también se conoce con la denominación de trabajo de campo, es uno de los principales métodos de investigación social. Sin duda, consiste en un paradigma de la llamada metodología cualitativa, aunque en un diseño de investigación es perfectamente combinable el acercamiento etnográfico con aproximaciones de carácter estadístico, como el análisis demográfico, o bien con técnicas de carácter sociométrico [...]. (PUJADA, 2010, p. 69).

Nesta linha, tracei os primeiros "rabiscos para desenhar" o método de investigação a partir da minha incursão no campo de pesquisa. Encarando o papel de pesquisador, constatei que Salvador possui seis (06) saunas masculinas, que são estabelecimentos privados destinados aos homens que buscam entretenimento, sociabilidade, relações sexuais, eróticas e amorosas (SANTOS, 2016). Esses seis (06) estabelecimentos estão divididos em duas modalidades, saunas com presença de garotos de programas e as que não aceitam garotos de programas em suas dependências. Essas modalidades de saunas estão presentes em várias cidades do Brasil, como observei nos estudos de Ribeiro (et. al. 2011), Santos (2012) e Santos (2016). Deste modo, as duas saunas existentes em Salvador, que proíbem a presença de garotos de programa em suas dependências, foram excluídas como espaços de observação deste trabalho etnográfico.

Entre os quatro espaços, eu selecionei dois. Os critérios de escolha foram os seguintes: a viabilidade da pesquisa, já que o tempo de execução do projeto da pesquisa foi de um ano (março de 2019 a março de 2020), neste curto tempo não seria adequado etnografar as trajetórias de vida dos interlocutores nas quatro (04) saunas; o não financiamento da pesquisa, tornando empecilho para o deslocamento e o pagamento da entrada nos locais; e a localização dos estabelecimentos que se situam em diversos bairros da cidade, alguns distantes entre si. Escolhemos as saunas situadas em localidades com maior facilidade de acesso por meio 
de transporte púbico, o que promove um número significativo de garotos de programa nesses estabelecimentos.

Feita a seleção das Saunas, recorri, mais uma vez, a Pujadas (2010, p. 70) que nos ofereceu "régua e compasso" na construção do desenho desta pesquisa, ao afirmar que "[...] observar y participar, zambullirse en la subjetividad de las vidas cotidianas los informantes, es lo que nos permite encontrar el sentido, comprender, lo que mueve y orienta las prácticas sociales y la cotidianidad de las personas." Mergulhei neste universo para desvendar a trajetória dos garotos de programas que tecem no cotidiano das saunas discursos, gestos, performances, estratégias inerentes ao mercado do sexo. Em uma realidade em que esses negociantes se reconhecem como viris, ativos, machos e heterossexuais (PERLONGHER, 2008; TEXEIRA, 2011; RIBEIRO, 2011; SANTOS, 2012; Neto e DIAS, 2015; SANTOS, 2016).

Como foi mencionado acima, na qualidade de andarilho urbano, eu já conhecia os dois espaços escolhidos, sabendo como funcionavam e quais as regras e os comportamentos adotados. Ser detentor desse conhecimento prévio desses espaços propiciou me aproximar com facilidade dos garotos de programa. Melhor dizendo, o entendimento prévio dos códigos e das regras daquele universo facilitou a interação com os interlocutores e foi interpretado por eles como uma identificação do pesquisador com o tema pesquisado. Um desses códigos é que todos os frequentadores da sauna devem estar de toalha, com ou sem roupa intima por baixo. Fazer a observação de campo e as entrevistas de toalha me colocou no mesmo patamar dos clientes. A minha presença sistemática não criou nenhum constrangimento para o cotidiano das casas. Consegui interagir com os frequentadores, por meio de conversas, brincadeiras, criando também uma sociabilidade propícia ao desenvolvimento da pesquisa etnográfica, que requer observação participante e participação observante.

Os "mergulhos" no campo de estudo ensejaram várias conversas informais com diferentes garotos de programa, explicitando aos mesmos do que se tratava a pesquisa. A minha presença constante em dias alternados da semana nas saunas teceu laços de confiança com os sujeitos da pesquisa. As conversas informais serviram como parâmetros para escolha dos interlocutores. Alguns garotos se dispuseram e outros se negaram a participar da pesquisa ${ }^{8}$. Destes contatos nas duas saunas, nove (09) garotos negaram participar da pesquisa. Já onze (11) garotos concederam

\footnotetext{
${ }^{8}$ Foram diferentes motivos apresentados pelos garotos para não conceder entrevista. Alguns garotos justificaram que não participariam da pesquisa por medo de ser identificado, mesmo após eu explicar que garantiria o anonimato das pessoas entrevistadas. Outros afirmaram que não teriam tempo para ser entrevistados, pois poderiam perder clientes no momento da entrevista.
} 
entrevistas. Deste número, seis (06) da Sauna A e cinco (05) da Sauna B. Além destas entrevistas, entrevistei os dois (02) proprietários dos respectivos espaços estudados. Das treze (13) entrevistas feitas, dez (10) foram gravadas, com o tempo de gravação de 30 a 60 minutos. Em três (03) entrevistas com garotos de programa não foi possível gravar, a pedido deles. As entrevistas foram manuscritas no diário de campo, depois que saí dos locais. No momento das entrevistas, utilizei guardanapos para registrar as narrativas.

Quase todas as entrevistas foram feitas nos recintos (no bar, nos quartos, no hall de entrada, no escritório da administração) das Saunas A e B. Só duas entrevistas com garotos de programa foram realizadas fora da sauna: uma foi em um restaurante e outra num bar, em dias diferentes. Essas entrevistas fora da sauna ocorreram com base nas propostas realizadas pelos respectivos garotos. Um disse que fora da sauna poderia ser melhor, pois garantiria a privacidade para que pudesse falar de sua vida, sem ser ouvido por ninguém. Já o outro pediu que saíssemos da sauna, pois ele estava com fome, "se eu poderia pagar um rango para ele, quando eu o entrevistasse". Eu concordei de imediato com as duas propostas. As duas entrevistas fora da sauna aconteceram sem problemas ou interferências de terceiros.

As entrevistas que ocorreram nas saunas apresentaram inúmeras dificuldades, atinentes aos locais: em geral, é proibido, nos espaços coletivos de convivência nas saunas (bar, sala de exibição de vídeo, corredores, etc.), o uso de celular, gravador, máquina fotográfica. Quando as entrevistas ocorreram no bar, o barulho externo, o som das músicas mecânicas e as vozes das pessoas presentes nesse ambiente também dificultaram as conversas com os garotos de programa. Essa dificuldade que demonstra uma característica sonora do campo de pesquisa me forçou a desenvolver estratégias para ter a atenção dobrada no momento da escuta para não perder o fio condutor da entrevista, ficar atento aos detalhes, como o silêncio, as pausas, as emoções, etc. Devido a essa situação peculiar, algumas entrevistas foram interrompidas, e remarcadas posteriormente, mas outras foram canceladas.

Algumas entrevistas foram realizadas no quarto. Eu tive, como qualquer outro cliente, de pagar a taxa de uso deste espaço, e limitar o tempo de entrevista, pois o tempo de permanência nesse recinto é no máximo 40 minutos, caso ultrapasse esse horário deveria pagar uma nova taxa. À frente explico melhor esse cômodo na estrutura arquitetônica das saunas.

Os garotos de programa, no momento da pesquisa, tinham entre 
18 a 41 anos de idade, a maioria era morador de bairros periféricos e do centro da cidade de Salvador. Outros moravam nos municípios da Região Metropolitana de Salvador, incluindo as Ilhas. Como destaquei acima, são homens que comercializam práticas sexuais, eróticas, desejos e companhia a partir da relação monetária com os clientes que, em sua maioria, estava na faixa etária de 30 a 70 anos de idade.

Com base nas entrevistas com os proprietários e conversas informais com os empregados (pessoal da limpeza, segurança, barman) dos respectivos estabelecimentos, somando com os dados contidos no diário de campo, identifiquei que a Sauna $A^{9}$, na ocasião deste estudo, somava cinquenta (50) garotos de programa registrados. Nos dias comuns, sem festas ou programações específicas, só trabalham, em média, vinte e cinco (25) garotos de programa. Já a Sauna B, adotando a mesma política, possuía em seu cadastro mais de cinquenta (50) garotos de programa, e em dias sem eventos, cerca de 30 exercem atividades no local. Ambas as casas utilizam o critério de tempo de atuação no estabelecimento, ou atratividade de clientes, para que os garotos de programa possam trabaIhar na casa todos os dias.

As saunas, observadas nesta pesquisa, possuem características e regras semelhantes, como as descritas nos distintos estudos que analisam saunas de algumas cidades brasileiras: Alexandre Teixeira (2011) que versa sobre a representação das atividades dos garotos de programas na cidade Belo Horizonte - MG, a partir do mapeamento das áreas de prostituição masculina (ruas, praças, boates e saunas); Miguel Ribeiro (et. al. 2011) analisa a dinâmica e a espacialidade das saunas da cidade do Rio de Janeiro RJ; Elcio Santos (2012) cuja investigação foca na relação da masculinidade e prostituição viril nas saunas da cidade de São Paulo-SP; e Daniel Santos (2016) que produz uma cartografia dos "boys/garoto de programa" nas saunas das cidades de Curitiba -PR, Florianópolis -SC, Porto Alegre - RS e São Paulo-SP. ${ }^{10}$

\footnotetext{
${ }^{9}$ Nesta pesquisa, não menciono os nomes das pessoas entrevistadas e nem das saunas observadas para que não sejam identificados, garantindo, assim, o sigilo. Identifico as duas Saunas como sendo Sauna A e Sauna B.

${ }^{10}$ Ao buscar nos bancos de dados digitais, não localizei nenhum estudo que verse sobre a realidade das saunas em Salvador. Portanto, este trabalho pode ser inédito, caso não haja nenhuma referência que investigou garotos programa nas saunas em Salvador. Há sete anos, apresentei uma comunição, intitulada "Desvelando o mercado do sexo: trajetória de vida dos garotos de programas de Salvador-BA", no Seminário Fazendo Gênero 10 de 2013. Essa comunicação se originou de um artigo incipiente, fruto de uma tentativa de pesquisa que não se realizou. Só no estágio pós-doutoral que tive o afastamento dos encargos das atividades da docência para me dedicar exclusivamente a pesquisa de campo e a leitura dos arcabouços teórico e metodológicos.
} 
As características principais, que se assemelham nas saunas pesquisadas, e não só nelas, são: primeiro, tanto clientes quanto garotos de programa pagam uma taxa para entrar na sauna. No entanto, o preço cobrado a eles é menor que o preço cobrado aos clientes. Na ocasião deste trabalho etnográfico, o valor era de $\mathrm{R} \$ 10,00$ nas duas saunas. Já o valor cobrado aos clientes é diferente em relação aos dias da semana. O valor dos clientes variava de $R \$ 30,00$ a $R \$ 35,00$, quando era nos primeiros dias da semana. E de quarta-feira a sábado, o valor transitava entre $\mathrm{R} \$ 35,00$ e 38,00 .

A segunda característica comum com outros trabalhos já citados, é que as dependências das saunas são distribuídas das seguintes maneiras: recepção ( $h a l l$ de entrada), salas de vídeo e televisão, a sauna propriamente dita, bar, palco para apresentações, quartos, cabines e banheiros. Além desses recintos, há um ambiente que tem armários com chave, para que clientes e garotos de programa possam guardar seus pertences (roupa, calçado, etc.). A regra geral, como critério estabelecido nas saunas, é que o público (os clientes e os garotos de programa) esteja nas dependências do estabelecimento de toalhas, que são oferecidas na recepção da casa, quando a pessoa adentra no recinto. A exceção para não uso da tolha como vestimenta só para pessoas que administram o local (proprietário e gerente), os empregados (pessoal da limpeza, segurança, barman) do estabelecimento, ou os artistas que irão se apresentar na casa naquele dia ${ }^{11}$.

Já a terceira característica comum é que há um horário fixo de funcionamento das saunas. Nos dois empreendimentos, o horário de funcionamento é das 15 às 22;00 horas. No entanto, nas sextas-feiras, nos sábados e nos feriados, o horário de funcionamento é das 15 às 23:00 horas. Também há horário determinado para que os garotos de programa possam entrar e sair dos respectivos estabelecimentos. Os que irão trabalhar nas saunas devem chegar das 15:00 às 17 horas e se ausentarem depois das 19 horas. Ou seja, devem ficar no estabelecimento no mínimo quatro (4) horas, tentando fazer programa com os clientes.

Ao conhecer as características e as regras comuns encontradas nas saunas investigadas e nas leituras dos trabalhos que abordam o tema, pude estabelecer as condições favoráveis à observação sistemática e participante no campo de estudo, pois, conforme relatei anteriormente, tive uma aceitação por parte dos clientes e dos garotos de programa, facilitando participar daquele espaço sem causar estranheza. As minhas percepções e conversas informais com clientes, garotos de programa, gerentes e empregados foram registradas no diário de campo, que se tornou uma

11 Para preservar o anonimato das saunas pesquisadas não irei apresentar as características peculiares de cada espaço. Só menciono a planta arquitetônica comum existente entre elas. 
das fontes de dados para serem analisadas a partir do arcabouço teórico erigido no decorrer da pesquisa.

Nesses estabelecimentos privados, homens se relacionam afetuosamente e sexualmente com base na interação comercial, onde o desejo, as fantasias, as performances corporais, os gestos e os discursos se transformam em mercadoria, substanciada por uma masculinidade, estabelecida, ideologicamente, como padrão. Na tentativa de entender a produção dessas expressões de gênero e masculinidade, recorri às formulações teóricas a respeito da masculinidade hegemônica. $O$ conceito de masculinidade hegemônica foi desenvolvido por Connel (1995) ao afirmar que a masculinidade se manifesta de acordo ao padrão predominante de ser homem, determinado culturalmente e historicamente. Esse modelo se baseia na distinção hierárquica em relação às mulheres e outras formas de masculinidades, as subalternas e as marginais. A masculinidade hegemônica se expressa negando a existência de outras formas de masculinidades e inferiorizando o feminino. Sobre este conceito, Connel e Messerschmidt (2013, p. 241), ao propor uma ampliação do conceito de masculinidade hegemônica, a partir das diversas críticas e as diferentes experiências no contexto atual, sublinham que:

[...] As masculinidades hegemônicas podem ser construídas de forma que não correspondam verdadeiramente à vida de nenhum homem real. Mesmo assim esses modelos expressam, em vários sentidos, ideais, fantasias e desejos muito difundidos. Eles oferecem modelos de relações com as mulheres e soluções aos problemas das relações de gênero. Ademais, eles se articulam livremente com a constituição prática das masculinidades como formas de viver as circunstâncias locais cotidianas. Na medida em que fazem isso, contribuem para a hegemonia na ordem de gênero societal [...] No nível local, padrões de hegemonia da masculinidade estão embutidos em ambientes sociais específi$\cos [\ldots]$.

Partindo desta perspectiva teórica, através das observações de campo e das entrevistas realizadas com os sujeitos desta pesquisa, posso afirmar que nos discursos, nas práticas, nas brincadeiras, nas performances corporais, na modulação do corpo, os garotos de programas reafirmam o modelo da masculinidade hegemônica, estabelecido socialmente como guia a ser seguido. Os garotos de programa que se relacionam sexualmente e, em alguns casos, amorosamente com outros homens, reforçam atitudes de macho viril, se referenciam por meio do padrão predominante de masculinidade. Quase todos, em suas narrativas, reivindicam para si a identidade normativa de gênero da heterossexualidade, a partir 
do vocábulo usual popularmente do "sujeito homem". Parece que este vocábulo é similar ao dito popular "homem de verdade", cuja existência é um marco do padrão de masculinidade (NOLASCO, 1997).

Esta peculiaridade analisada na incursão do campo de estudo, se assemelha com os resultados obtidos por Perlongher (2008), em seu estudo clássico sobre a "prostituição viril" em São Paulo, quando assevera:

Como os michês entrevistados "em profundidade" o revelam, gabar-se de heterossexualidade soma pontos perante os clientes, que, em grande parte, procuram rapazes que não sejam homossexuais. Aqui, nos encontramos com um primeiro paradoxo que vai marcar o negócio todo. Num apreciável número de casos, os rapazes que se prostituem não são ou não se consideram homossexuais e esta recusa da homossexualidade vai ao encontro das demandas dos clientes (PERLONGHER, 2008, p. 48).

Nesta linha interpretativa, Miskolci e Pelúcio (2008, p. 12), ao prefaciarem a segunda edição da referida obra, sublinham que:

O desejo pelo "homem de verdade", ou seja, pelo padrão de masculinidade idealizado no contexto brasileiro, é o que guia o negócio. O "homem de verdade" é o homem heterossexual. Seu culto demonstra como o desejo por alguém do mesmo sexo pode se associar a um conformismo à ordem heterossexual, às suas normas de gênero, aos seus padrões estéticos e até à gramática das relações sexuais.

A partir desta discussão teórica, inquiro como jovens que se autodenominam de heterossexuais, buscam as saunas, locais que integram a "cena homossexual" da cidade, para exercerem atividades relativas ao mercado do sexo com outros homens? Para tratar dessa suposta contradição, recorri às memórias dos garotos de programa como meio de entender quais os caminhos trilhados que os conduziram aos locais, onde podem oferecer serviços sexuais e eróticos para outros homens. Essas atividades exercidas por esses jovens se configuram, também, como estratégia de sobrevivência em que geram ou contribuem com a renda familiar, ainda que não seja apenas essa a motivação, pois o desejo, o afeto e a sociabilidade são elementos que se tecem na dinâmica desse mercado. Nesta investigação etnográfica, parto da discussão das memórias subterrâneas, desenvolvida por Pollak (1989, p. 4), quando o autor assevera que:

Ao privilegiar a análise dos excluídos, dos marginalizados e das minorias, a história oral ressaltou a importância de memórias subterrâneas que, como parte integrante das culturas minoritárias e dominadas, se opõem à "Memória oficial", no caso a memória na- 
cional. Num primeiro momento, essa abordagem faz da empatia com os grupos dominados estudados uma regra metodológica e reabilita a periferia e a marginalidade.

Essas memórias estão guardadas no refúgio do silêncio, ou ignoradas, pertencem aos excluídos, aos marginalizados da sociedade. No caso desta pesquisa, são jovens que parecem invisíveis e são tratados como perigosos, ou marginais. As suas lembranças são vivas e se constituem "subversivas no silêncio", transmitidas dentro dos seus circuitos de amizades. Os jovens, ao narrarem suas lembranças, confinadas no silêncio, revelam como iniciaram sua trajetória como garoto de programa. No conjunto das entrevistas, observei diferentes formas: círculo de amizade, vínculo familiar e aplicativos, ou sites. A maioria desses garotos acessou o universo da prostituição masculina pelas redes de amizade ou por laços familiares. Parece existir uma rede de solidariedade entre eles, pois ao divulgar, de boca em boca, a existência das saunas, permitem que outros jovens, amigos ou familiares, possam ter um meio de gerar renda e um espaço que garanta a realização de seus desejos, afetos e amores com outros homens.

Em uma sociedade em que há vigilância da masculinidade para que ninguém se afaste do modelo ideal de ser homem, um homem vender serviços sexuais para outros homens, pode produzir situações constrangedoras e, até mesmo, estigma no grupo social (familiar, vizinhos, amigos, etc.). Então, quebrar esse segredo, ao compartilhar a informação, possibilita criar laços de cumplicidade e confiança entre esses jovens. Assim, essas memórias relacionadas às experiências no mercado do sexo se inserem no campo do silêncio, do não dito, ou seja, nas memórias "subterrâneas" (POLLAK, 1989).

Como observei nas entrevistas e nas conversas informais, alguns garotos de programa possuem experiência em se relacionar sexualmente com outros homens antes de iniciarem suas atividades na sauna. Geralmente, essa relação aconteceu com homens que moram no mesmo bairro, ou próximo à moradia desses jovens. Com isto, posso afirmar que tal situação integra-se no contexto cultual onde o papel sexual masculino é definido pelo pênis penetrador, daquele que penetra a vagina e pode também penetrar o ânus de outro homem. O homem ativo, o penetrador, é a marca do macho viril, da masculinidade idealizada. Neto e Rios (2015, p. 258), em seu estudo etnográfico sobre homens que comercializam prazeres nas ruas do centro da cidade de Recife-PE, abordam que:

Ainda que as práticas homossexuais sejam condenadas pela moral sexual do senso comum, nas classes populares há certa licença para o homem que se coloca na posição de ativo. Como macho, ele pode penetrar todos, mulheres e bichas. Os boys [garotos de 
programas] enfatizam a assertiva de que o macho de verdade é aquele que come, que ganha sentidos de dominação e subjugação por meio do ato sexual.

Esta estrutura hierárquica que estabelece a relação entre o ativo (o penetrador) e o passivo (penetrado) reforça o modelo de masculinidade predominante na sociedade. $\mathrm{O}$ ativo se refere ao macho viril e o passivo se identifica ao feminino. A dicotomia entre ativo, o superior, e passivo, o inferior, reitera comportamentos, gestos, discurso, vocábulo presentes no universo sexual, e sedimenta na sociedade o estigma de pessoas que se enquadram como passivo no intercurso sexual (MISSE, 2007). O garoto de programa reivindica para si o papel de gênero do macho ativo, o penetrador. Já o outro na relação é o passivo, a bicha, o viado, colocado assim no lugar de inferioridade. Como explicitado no trecho na fala de um entrevistado: "[...] vim aqui [a Sauna A] para comer uns viados e ver se ganho uma grana [...]" (Garoto de Programa 3A, 2019). O sentido dessa fala não é isolada na narrativa desse garoto de programa, mas se constitui como marca presente da cultura do mercado do sexo, delineado no cotidiano desses espaços.

Nesta linha de análise, presenciei no cotidiano das saunas, algumas brincadeiras, conversas, discussões e desentendimentos entre os garotos de programa que reforçam uma espécie de vigilância da masculinidade desses garotos, tal como afirma Damatta (1997, p. 37), em artigo que traça as memórias das brincadeiras de sua juventude, quando nos diz que: "um dos preços da masculinidade, portanto, era [é] uma eterna vigilância das emoções, dos gestos e do próprio corpo".

Os jovens pesquisados necessitam demonstrar que se enquadram no modelo de masculinidade hegemônica. Sair desse modelo pode ocasionar constrangimentos e, às vezes, até conflitos. Além de causar uma propaganda negativa para os demais, nas transações sexuais com os clientes, como mencionaram quatro deles, dois por meio das conversais informais, e dois por meio da entrevista:

[...] como [transo] os caras aqui [na sauna] por dinheiro, mas sou homem, não gosto de boys que munhecam e ficam na brincadeira de passar a mão na bunda dos outros (Garoto de Programa 1A, 2020).

[...] Se o boy é uma bichinha, a porra queima o filme dos outros boys, pois os clientes irão achar que todos dão o cu, e a gente perde [...]. [...] a maioria dos clientes querem pau (Garoto de Programa 2A, 2019). 
[...] O cara gosta de ser passivo, não deve dar pinta no bar, tem que ter atitude de homem aqui, né.[...] (Garoto de Programa 6A, 2019).

Com base nos trechos acima destacados, se o garoto de programa for afeminado ou explicitar que prefere ser passivo na prática sexual, ou sendo, como denomina Perlonher (2008 [1987]), "michê-bicha", fere 0 atributo da masculinidade perseguido pelos demais. Por isto, boa parte deles nega que se relaciona sexualmente com cliente como passivo. Dos onze entrevistados, três afirmaram que se o cliente oferecer uma quantia compensadora, eles podem aceitar ser passivos no ato sexual. Essa informação deve ficar restrita entre quatro paredes, ou seja, só as pessoas envolvidas compartilham essa informação, tornando-se um segredo.

Quando esse pacto do silêncio é transgredido pode gerar comentários que estigmatizam. Essas informações tornam-se fonte de fofocas, insinuações, brincadeiras que geram discussões, agressões, inimizades, perdas de confiança, entre outros aspectos. Notei que os comentários recorrentes nos espaços observados reforçam a vigilância da masculinidade, forjadas entre os garotos de programas. Ser passivo explicitamente fere o modelo perseguido e adotado como atrativo para comercialização das práticas sexuais.

No cotidiano de trabalho nas saunas, os garotos de programa produzem suas estratégias de sedução e muitos recorrem ao olhar para iniciar sua abordagem com os clientes, abrindo caminho para o primeiro contato. É com o olhar que os garotos percebem o grau do desejo do cliente, se o mesmo é receptivo ou não. Também o olhar encena as primeiras formas de seduzir e mexer com as fantasias do cliente, é um diálogo silencioso, auxiliado pelos gestos e sinais. Um determinado olhar possibilita que 0 cliente se aproxime e inicie o jogo da sedução. Além do olhar como os primeiros passos para a sedução, alguns reforçam outros atributos para atraírem possíveis clientes, como narraram os jovens:

[...] O meu corpo, a minha altura e o tamanho do pau é do agrado da galera [clientes]. Também a minha conversa de mandão, os caras piram (Garoto de Programa 3A, 2019).

[...] Primeiro lugar, eu acho que é questão do visual. Eu tenho um corpo assim, definido, eu tenho um pênis, assim, do tamanho acima da média, então eu acho que esse impacto inicial é o que atrai inicialmente o cliente. Depois é a forma que eu chego, que eu converso, a forma que eu tento excitar o cliente. As coisas que eu vou falando pra ir estimulando o imaginário dele e ir excitando ele. Mas eles gostam do tamanho do meu pau e da pegada de macho 
(Garoto de Programa 4A, 2019).

Na forma da pessoa ser. Da conversa e saber fazer. E também do "dote" do cara, né. Da pica. Da pica dura. E tal, da pegada gostosa [risos] Aí, o cliente gosta. De chegar e ter um papo bom. Eu garanto que ele vai gostar (Garoto de Programa 1B, 2019)

Eu sou "bem-dotado", aparentemente eu tenho $22 \mathrm{~cm}$. Então, o quê, eu tenho um corpo legal, não sou bonito, mas sou simpático, tanto de corpo quanto de rosto. Então, se adaptar é isso. É você sobreviver no mundo que a gente tá (Garoto de Programa 2B, 2019).

Seduzem os clientes, por meio da conversa, das insinuações eróticas, das gesticulações, do corpo jovem e/ou másculo, da exibição pública da ereção do pênis, e se esse tiver o dote acima da média poderá atrair muito mais. Essa sedução tem o objetivo de nutrir a fantasia dos frequentadores das saunas que, na maioria das vezes, buscam gestos e atitudes viris, másculos e de fala dominadora do macho. Essa sedução por meio do corpo, com o passar do tempo e da experiência, ganha outros ingredientes. Eles passam a desenvolver habilidades, práticas e valores, a partir de sua vivência no trabalho. Tal habilidade possibilita um desempenho satisfatório, materializado no ganho do dinheiro, como salienta um deles:

De um ano e meio que venho pra cá [a sauna] eu, graças a Deus, sou um cara muito cabeça e observador. Eu venho observando que na casa tem clientes de vários tipos: Tem aquele que quer usar o boy, tem aquele que quer ajudar e tem aquele também que quer [transar]. Quem vem só pra satisfazer sua vontade e ir embora, trata a gente como objeto, entendeu? E nesse meio, é um meio que você tem que observar mais do que falar demais. É como qualquer outro meio de trabalho. Tem que observar mais e falar menos. Assim, você vai sempre ganhar e não perder (Garoto de Programa 1A, 2019).

[...] tenho alguns cliente porque sei lidar com as pessoas, né, sei tratar as pessoas com respeito e bem. De repente é porque eu me coloco na posição da pessoa, eu me imagino como eu gostaria de ser tratado, então, eu trato da mesma forma [...] Aprendi com a experiência desse trabalho, o cliente quer putaria, mas quer atenção. (Garoto de Programa 4A, 2019).

[...] Há situações difíceis que você tá com um cliente, e outro boy chega, aí você tem que arrumar um jeito de não perder o cliente. Porque outro boy tá próximo a você, então, tem de ficar de olho no cliente. Aí se torna como se fosse uma disputa, mas não por 
causa do cliente, e sim por causa da grana, porque todo mundo tá em busca da mesma coisa, né, que é o dinheiro. Então, tenho que ter o verbo para dar em cima do cliente. Sei que o cliente quer também atenção, carinho e conversa [...]. Descobri isto. (Garoto de Programa 2B, 2019)

Com a experiência da vida, né, antes eu pensava que só era chegar e pegar a chave [do quarto], e dar pica ao cliente, Não é isto. Depois eu comecei a entender que deveria ter uma atenção, que deveria ter algo mais [...], se o cliente quer carinho, eu dou. O meu atrativo para os meus clientes é a forma de conversar, minha boniteza, que sou uma pessoa muito bonita [risos]. Minha forma de conversar, de andar, de me vestir, do meu comportamento, esses são os meus atrativos. E daí, começa quando vai pro quarto, no quarto eu dou meu cem por cento e pronto. Aí completa tudo, junta o útil com o agradável (Garoto de Programa 3B, 2019).

Em meio à experiência das atividades da sauna, os garotos aprendem como lidar com situações do cotidiano do trabalho e assimilam regas, normas tecidas na sociabilidade daqueles espaços que favorecem o mercado do sexo e garantem o sustento para os boys e seus familiares, por outro lado, esses mesmos espaços podem se constituir como lugares onde se realizam desejos e encontros amorosos entre os garotos e os clientes, ou entre os próprios garotos.

Nesta linha de análise, cabe aos garotos de programa e aos clientes, de forma direta, sem a interferência dos proprietários e/ou gerentes, acordarem o valor do programa. Na grande maioria, as negociações são realizadas antes dos clientes e dos garotos de programa entrarem nos locais privados (quartos ou cabines). Os primeiros contatos entre os garotos de programa e os clientes se dão nos espaços coletivos (no bar, nas salas de vídeo, nos corredores, no ambiente dos armários, na sauna propriamente dita) dos estabelecimentos. São nestes espaços que se estabelecem os acordos, os preços são definidos, quais serão as práticas sexuais eróticas, quem será ativo e/ou passivo, se terá sexo oral, sexo anal, se será "um sarro", se no ato sexual haverá ejaculação, ou presença de outro garoto de programa, e/ou outro cliente, entre outras peculiaridades. Também alguns boys, mediante a um acordo, atendem os clientes em sua residência, ou em hotéis/motéis, fora do horário de funcionamento das saunas.

Em relação ao preço estabelecido na comercialização do sexo, os garotos de programa, conjuntamente com a gerência e/ou o proprietário da sauna, fixam a quantia mínima para o programa, que, no momento da 
pesquisa, custava entre $\mathrm{R} \$ 70,00$ a $\mathrm{R} \$ 100,00$. Este valor pode diminuir ou aumentar mediante as negociações estabelecidas e os acertos em relação às práticas que serão realizadas durante o ato sexual. $O$ valor recebido dos clientes pelos serviços sexuais é exclusivo dos garotos de programas, não há nenhum percentual que fica na casa. Os garotos de programa pagam a entrada e o que consomem no bar. Na tessitura da negociação do preço do programa, o valor aumenta se o garoto tiver que ejacular, for passivo (ser penetrado pelo cliente), ou realizar qualquer outra prática fora do corriqueiro. Caso o garoto de programa ejacule na relação, pode perder a ereção e ter um desempenho desfavorável em outro programa, por isto, o valor é maior que possa ser recompensado com a perda de ereção momentânea, depois da ejaculação.

Como a ereção é uma das formas atrativas para maioria dos clientes, no processo de venda das práticas sexuais e eróticas, muitos garotos de programa utilizam medicação para adquirir a ereção por várias horas e com diferentes clientes, como nos elucidam quatro entrevistados:

90 ou $80 \%$ das pessoas que eu conheço, os que são boys, que trabalham junto com a gente, utilizam o Citrato ${ }^{12}$, que é um genérico do Viagra. Então, assim, muitos não tem esse tesão naturalmente. Muitas vezes também é uma questão associada ao 'psicológico': Você tem que tomar o azulzinho pra poder funcionar. É raro, na verdade, ter um cliente que seja compativel com nosso gosto, então, na maioria das vezes, a gente tem que usar o 'psicológico', tipo: tem que se abster, tem que se lembrar de uma situação que seja excitante, tem que lembrar de um momento realmente que te traga tesão [...]. (Garoto de Programa 4A, 2019).

Olha, não vou mentir, vou the dar a real, todo mundo usa o azulzinho. Não tem esse que consiga ficar com o pau duro o tempo todo. Já tem gente aqui viciado, só transa com essa porra. Tem cliente que faz um boquete gostoso, aí sobe, mas tem uns, que só o "azulzinho" para subir e ficar horas e horas com o pau duro, isto não é natural, só usando a porra mesmo (Garoto de Programa 5B, 2019),

12 "O citrato de sildenafila é indicado para o tratamento da disfunção erétil, que se entende comosendo a incapacidade de obter ou manter uma ereção (rigidez do pênis) suficiente para um desempenho sexual satisfatório. Para que este medicamento seja eficaz, é necessário estímulo sexual." Disponível em: https://www.minhavida.com.

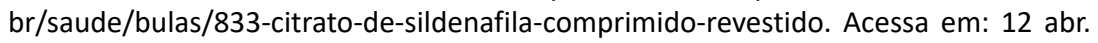
2020. Esse medicamento genérico é conhecido entre os boys de "azulzinho". Ele também é mais barato que os outros medicamentos existentes nas farmácias do país. 
As narrativas acima demonstram que o pênis é fundamental para o comércio sexual. $O$ "pau" é o elemento que exprime a masculinidade aceita socialmente. Esse elemento deve ser exibido para que todos possam ver e, em alguma ocasião, pegar. Se o pênis não fica ereto, naturalmente, os boys, como estratégia, utilizam remédio para estimular a ereção e exibir sua hombridade por meio da dureza do pênis (DAMATTA, 1997). Outro aspecto, analisado na imersão do campo, que ao abordar sobre o odelo ideal de masculinidade, cujo intento é transformá-lo em mercadoria no cotidiano das saunas, é necessário articular esse modelo com os debates postos sobre a masculinidade negra. Dos que tivemos contato, por meio da entrevista, quatro (04) se declararam branco, moreno claro. E sete (07) afirmaram ser negro, ou pardo, ou preto, ou moreno escuro. Para além da constatação da cor da pele dos onze (11) garotos de programas, necessitamos analisar as sutilezas que o marcador social étnico racial/cor se apresenta no processo, cotidiano, de reafirmação do modelo de masculinidade hegemônica. Presenciamos vários acontecimentos que envolveram a distinção racial entre brancos e negros, e a hipermasculinização e maior objetificação dos corpos dos negros. Selecionei, aqui, três episódios que descrevo abaixo no intuito de ilustrar minha argumentação:

O primeiro episódio se deu na Sauna B, quando presenciei a conversa entre três garotos de programa. Nesse diálogo, "um deles reclamava, porque havia dois dias que ele não fazia nada [Ou seja, não fez nenhum programa com cliente, portanto não recebeu dinheiro]. Continuou sua narrativa, afirmando que não fazia muito programa, não por ter um 'pau pequeno', mas por ser branco, bonito e inteligente e ter o pau pequeno. Só os clientes inteligentes, com dinheiro e estudados o procuravam. Já os de pau grande, que são negros, feios e sem estudo, atraem pessoas [clientes] com pouca grana e sem estudo, que só querem pauzão." O segundo episódio ocorreu na Sauna A, quando eu ouvi clientes afirmarem que preferiam aquela sauna, porque havia um maior número de cafuçus [na gramática da cultura homossexual, cafuçu significa homem negro, viril, rústico e trabalhador braçal das classes populares]. O último episódio aconteceu na Sauna B, no momento em que uma artista, conversando com alguns clientes, afirmou que uma determinada sauna, situada em um bairro nobre de Salvador, tinha outro nível de garotos de programas, malhados em academia, bonitos, mais elegantes.

Nos três trechos há uma visão de que o negro tem um pênis acima da média, figurando em uma hipersexualização do negro, e que ser negro é sinônimo de feio e pobre. Essa visão se baseia no racismo, que se estrutura na trajetória histórica brasileira e produz uma base ideológica 
que alimenta discursos e práticas na dinâmica social. O racismo consolida hierarquias entre o branco, superior, e o negro, inferior, configurando distinções que entendem o branco como bonito, inteligente e rico, e o negro como feio, ignorante e pobre. Essa interpretação se aproxima da análise de Pinho (2019, p. 125), quando diz que:

A transformação do terror, violência e racismo da escravidão, encontrada na reconexão histórica e subjetiva do homem negro como corpo e o sexo, cria uma fronteira fatal. O Corpo negro, concebido como mapa barbarizado do imaginário colonial e da luta de classe, materializa os sujeitos raciais como "ilegítimos", figuras abjetas, entendidas como tal na perspectiva de uma civilização universalista.

O racismo, como estruturante, entremeia as sociabilidades ensejadas no cotidiano das saunas, e se manifesta nos discursos, nas brincadeiras, nas insinuações, nos apelidos e, sobretudo, no campo dos desejos, cuja materialidade se dá nas fantasias sexuais (os fetiches). $O$ garoto de programa negro, de acordo com os relatos dos episódios acima descritos, é interpretado como "corpo negro" hipermasculinizado que possui um "pau grande" e erétil, e um apetite animalesco para o sexo. Mesmo com essa suposta vantagem na concorrência no mercado do sexo, esse corpo é também visto como feio, ignorante e pobre.

Ainda sobre o processo da hipermasculinidade dos homens negros que fazem programa com outros homens, alguns clientes buscam os espaços frequentados por "cafuçus". São também portadores de atributos sexuais, o pênis avantajado, e incansáveis no ato sexual. Essas características alimentam as fantasias sexuais por meio do fetiche. Frente a essa análise, mais uma vez, recorro a Pinho (2004, p. 67), em outro artigo, quando diz:

Assim, o corpo negro masculino é fundamentalmente corpo-para-o-trabalho e corpo sexuado. Está, desse modo, decomposto ou fragmentado em partes: a pele; as marcas corporais da raça (cabelo, feições, odores); os músculos ou força física; o sexo, genitalizado dimorficamente como o pênis, símbolo falocrático do plus de sensualidade que o negro representaria e que, ironicamente, significa sua recondução ao reino dos fetiches animados pelo olhar branco

O padrão de masculinidade forjada pelos jovens garotos de programa das saunas de Salvador, transformada em produto a ser comercializado, não se dá de forma homogênea, traz consigo marcadores de classe social, de raça, de orientação sexual e de territorialidade. A racialização do desejo aparece na interpretação que alguns clientes possuem em relação 
ao "corpo negro". O cafuçu, incansável no ato sexual, torna-se substância para as fantasias sexuais, esses jovens negros, na maioria das vezes, são percebidos como feios, deselegantes e corpos animalescos.

O meu processo de metamorfose do flâneur para o investigador etnográfico permitiu adquirir outro olhar sobre masculinidade e mercado do sexo. A masculinidade valorizada nesses espaços, tanto pelos garotos de programas quanto pelos clientes, se alicerça no padrão estabelecido no que é ser homem de verdade. No entanto, na dinâmica cotidiana das saunas outras, formas de masculinidades não hegemônicas se fazem presentes e interagem com esse modelo de masculinidade comercializado. Por isto, posso afirmar que a virilidade, a dominação e a centralidade do falo se mesclam com desejo, prazer, interações afetuosas e amorosas realizadas entre os homens (garotos de programas e clientes) que frequentam as saunas pesquisadas.

\section{REFERÊNCIAS}

CONNEL, R. Masculinities. Berkeley: university of California Press, 1995.

CONNELL, R. W.; MESSERSCHIDT, J. W. Masculinidade hegemônica: Masculinidade hegemônica: repensando o conceito. Estudos Feministas, Florianópolis, v. 21, n.1, p. 242-282, jan./abr. 2013.

DAMATTA, R. Tem Pente Aí? Reflexões sobre a Identidade Masculina. In: CALDAS, Dario. (org.) Homens. São Paulo: Editora SENAC, 1997. p. 51-92.

MISKOLCI, R. Desejos digitais: uma análise sociológica da busca por parceiros on-line. Belo Horizonte: Autentica, 2017.

MISKOLCI, R.; PELÚCIO, L. Aqueles não mais obscuro negócio do desejo Prefácio. In: PERLONGHER, N. O negócio de michê: a prostituição viril em São Paulo. 2. ed. São Paulo: Editora Fundação Abramo, 2008. p. 9-32.

MISSE, M. $O$ estigma do passivo sexual: um símbolo de estigma no discurso cotidiano. $3^{\circ}$ Edição. Rio de Janeiro: Booklink: NCVU/IFICS/UFRJ: LeMetro/IFICS/UFRJ, 2007.

NETO, E. N. S.; RIOS, L. F. Apontamento para uma economia política do $\mathrm{Cu}$ entre trabalhadores sexuais. Psicologia \& Sociedade. Belo Horizonte, vol.27, n.3, set./dez. 2015 . p. 579-586. Disponível em: scielo.br.scielo?pid S10271822003005\&scripabstrac\&tingpt. Acesso em: 15 mar. 2020.

NOLASCO, Sócrates. Um "Homem de Verdade". In: CALDAS, D. (org.) Homens. São Paulo: Editora SENAC, 1997. p. 13-30.

PENTEADO, F. M.; GATTI, J. Masculinidades: teoria, crítica e artes. São Paulo: Estação das letras e cores, 2011. 
PERLONGHER, N. O negócio de michê: a prostituição viril em São Paulo. 2. ed. São Paulo: Editora Fundação Abramo, 2008.

PUJADAS, J. J (coord.); ARGRMIR, D. C. d'; GIRONA, J. I. Etonografía. Bacelona: Editorial UOC, 2010.

PINHO, O. Qual a identidade do homem negro?. Revista Democracia

Viva. IBASE. Rio de Janeiro, n. 22, p. 64-69, jun. 2004.

PINHO, O. O corpo do homem negro e a guerra do sexo no Brasil. In: RESTIER, H.; SOUZA, R. M. de. Diálogos contemporâneos sobre homens negros e masculinidade. São Paulo: Ciclo Contínuo Editorial, 2019. p. 105-130.

POLLAK, M. Memória, esquecimento, silêncio. Estudos Históricos, Rio de Janeiro, v. 2, n. 3, p. 3-15, jan./junh. 1989.

RIBEIRO, M. A.; OLIVEIRA, R. da S.; MAIA, G. da S. Dinâmica e Espacialidade das saunas de boys na cidade do Rio de Janeiro. Revista Latina Americana de Geografia e Gênero, Ponta Grossa, v. 2. n. 2, p. 57-65, ago./dez. 2011.

RIO, J. do. Alma encantadora das ruas: Crônicas. São Paulo: Companhia da Letras, 2008.

SANTOS, É. N. dos. Amores, vapores e dinheiro - masculinidades, homossexualidades nas saunas de Michê em São Paulo. 2012. . Tese de Doutorado em Ciências Sociais do Programa de Pós-Graduação em Ciências Sociais, Pontifícia Universidade Católica de São Paulo, São Paulo, 2012. p. 1-238.

SANTOS, D. K. do. Homens no mercado do sexo: fluxos, territórios e subjetivações. 2016. Tese de Doutorado em Psicologia do Programa de Pós-Graduação em Psicologia, Universidade Federal de Santa Catarina, Florianópolis, 2016. p. 1-372.

TEIXEIRA, A. E. Representação sobre a atividade de garotos de programas em Belho Horizonte: emprego, trabalho ou Profissão? In: XI CONLAB - CONGRESSO LUSO AFRO BRASILEIRO DE CIÊNCIAS SOCIAIS, 2011 Salvador. Anais eletrônicos...,Salvador, XI CONLAB., 2011. p. 1-16. Disponível em: www.xiconlab.eventos.dupe.com.br/anais3/1308350926_arquivo. Acesso em: 19 out. 2019. 